\title{
Cloning of two genes encoding Rab7 in Paramecium
}

\author{
Liliana Surmacz, Jolanta Wiejak and Elzbieta Wyroba ${ }^{\bowtie}$ \\ Nencki Institute of Experimental Biology, Department of Cell Biology, Warszawa, Poland; \\ $\otimes_{e-m a i l: e . w y r o b a @ n e n c k i . g o v . p l}$
}

Received: 26 September, 2005; revised: 21 October, 2005; accepted: 21 November, 2005

available on-line: 19 December, 2005

\begin{abstract}
Rab7 is a small GTPase that plays a crucial role in the regulation of transport from early to late endosomes and lysosomes, phagosome maturation and in lysosomal biogenesis in mammalian cells. It contains conserved and unique sequence elements that mediate its function. Two $R a b 7$ genes, $R a b 7 a(703 \mathrm{bp})$ and $R a b 7 b(707 \mathrm{bp})$ were identified in the unicellular eukaryote Paramecium by PCR amplification. They contain three short introns of different lengths (28-32 bp) and sequence located at identical positions in both genes. The presence of two Rab7 genes in the Paramecium genome was confirmed by Southern hybridization analysis performed with six different restriction enzymes. Expression of both genes was assessed by Northern blot and RT-PCR. Two transcripts of $\mathbf{1 . 8}$ and $2.2 \mathrm{~kb}$ were identified by hybridization analysis. The cloned complementary DNAs, both of 618 nucleotides in length, encode polypeptides of 206 amino acids that are $97.6 \%$ identical and differ in their C-termini. The predicted protein sequences of Rab7a and Rab7b contain all characteristic domains essential for Rab function: the effector domain (YRATVGADF) and four GTP-binding consensus sequences (GDSGVGKT, WDTAGQ, NKLD, SAK) as well as the prenylation motif $(-\mathrm{CC})$ at the C-terminus indispensable for Rab binding to the membrane. Similarity searches revealed $81.6-82.1 \%$ homology of Paramecium Rab7 isoforms to human Rab7 and a lack of an insert typical for the Kinetoplastida - the species that appeared earlier in evolution. Paramecium is the first free-living lower eukaryote in which homologues of Rab7 have been identified that exhibit features similar to those of mammalian Rab7.
\end{abstract}

Keywords: Rab7, Paramecium, cloning, hybridization, digoxygenin labeling, PCR/RT-PCR

Rab family of small GTPases regulate transport of endo- and exocytic vesicles and are involved in the control of their docking and fusion in mammalian cells (Chavrier et al., 1991; Saraste et al., 1995; Van der Sluijs \& Gerez, 1999; Somsel Rodman \& Wandinger-Ness, 2000). More than 60 Rab GTPases are known and they have been localized to the surface of intracellular compartments (Pereira-Leal \& Seabra, 2001; Pfeffer \& Aivazian, 2004).

Rab proteins contain conserved and unique sequence elements that mediate their function. The highly conserved regions include the effector domain, the guanine base- and phosphate-binding motifs and a cysteine motif which is posttranslationally modified by the geranyl-geranyl lipid group and is required for the interaction of Rab protein with GDI and membranes. Multiple factors contribute to the specificity of Rab localization to distinct intracellular membranes (Seabra \& Wasmeier, 2004), including a unique sequence motif called hypervariable region (Chavrier et al., 1991; Bruckert et al., 2000; Moyer \& Balch, 2001).

Compounds internalized by different endocytic pathways enter the late endosomal compartment in which Rab7 regulates their rate of degradation (Feng et al., 1995; Bruckert et al., 2000). Much attention is focused on Rab7 GTPase since a mutation in its gene evoking neuropathy of Charcot-Marie-Tooth type 2B was recently discovered (Verhoeven et al., 2003). Rab7 plays an important role in the regulation of cholesterol level (Bruckert et al., 2000), production of thyroid hormones (Croizet-Berger et al., 2002) and accumulation of unprenylated Rab27A in choroideremia (Rak et al., 2004). It is also involved in entering of viruses and bacteria (Meresse et al., 1999; Sieczkarski \& Whittaker, 2003). The expression level of this protein in different

^Accessions numbers: Sequences of Rab7a and Rab7b have been deposited in the GenBank database under the following numbers: cDNA sequences: AY744503, AY644723; genomic sequences: AY050242, AY875981; amino-acid sequences: AAL08054, AAW68046.

Abbreviations: RILP, Rab-interacting lysosomal protein; RabSF, Rab subfamily; GDI, GDP dissociation inhibitor. 
cells correlates with the endocytic/phagocytic activity (Desjardins et al., 1994; Bruckert et al., 2000; Rupper et al., 2001). Rab7 plays a crucial role in the regulation of trafficking from early to late endosomes and lysosomes, phagosome maturation and in lysosomal biogenesis (Pfeffer \& Aivazian, 2004).

In the present study we describe the first members of the Rab family in the free-living ciliate Paramecium. Ciliates emerged early in evolution prior to yeasts, plants and animals (Sogin \& Elwood, 1986). Many components of the trafficking and signaling pathways are conserved from ciliates to humans (Luporini et al., 1994; Subramanian et al., 1994; Wyroba et al., 1995; Creutz et al., 1998; Kissmehl et al., 2002; Wiejak et al., 2004b) but the molecular machinery underlying endocytic processes has not yet been fully elucidated in these unicellular eukaryotes. We have previously characterized components participating in the early stages of endocytosis and identified two partial genes encoding dynamin. Paramecium seems to be the most ancient cell in which dynamin performs its function as in the Metazoa - in clathrin-mediated endocytosis (Wiejak et al., 2004b) and in agonist-induced receptor desensitization (Wiejak et al., 2004a).

Here we identified a component of the late endocytic pathway by cloning two genes and complementary DNAs coding for Rab7. The predicted amino-acid sequences of Paramecium Rab7 exhibit very high homology to mammalian counterparts and contain the characteristic domains indispensable for Rab protein function. DNA/RNA hybridization analyses confirmed the presence of two genes and two mRNAs for Rab7 in Paramecium.

\section{MATERIALS AND METHODS}

Cells. Paramecium octaurelia strain 299s (5-dayold axenic culture) was cultivated and harvested as reported (Wyroba, 1987).

PCR/RT-PCR and cloning. PCR/RT-PCR amplifications were performed using genomic DNA $(0.75 \mu \mathrm{g})$ isolated from Paramecium (Subramanian et al., 1994) or cDNA, respectively, as templates in a PTC-200 DNA Engine thermocycler (MJ Research, Inc.). cDNA was obtained by reverse transcription of $1 \mu \mathrm{g}$ of total RNA with the Enhanced Avian RT-PCR Kit with oligo-dT primers according to manufacturer's instruction (Sigma-Aldrich Chemie $\mathrm{GmbH}$ ). Several primers were designed to the nucleotide sequence of highly conserved regions of Rab7: the effector domain, RabSF (Rab subfamily) motifs, and G3 binding domain from different species and synthesized according to the ciliate nuclear codon usage (Martindale, 1989). Subsequently, next sets of primers were constructed to the sequence of the Rab7 gene fragments obtained during cloning. The forward primers were: 5'-TATAAAGCTACAATTGGAGCTGATTTC, 5'-CCATTCGTTGTTTTAGGA, 5'-ATGGCCAGCCAGAAGAAGCAA, and the backward ones: 5'-TCCTAAAACAACGAATGG, 5'-ACAACATCCTCCTTATTTGG, 5'-ACAACATCCTCC TTATTTGGCTTATGGTTTTTGGCTC, 5'-ACAACATCCTCCTTATTTGGTCTATTTCTTTGG GTCT. PCR setting, cloning into pGEM-T Easy vector (Promega), transformation of competent Escherichia coli bacteria (JM109) and selection of positive clones were performed as described previously (Wiejak et al., 2004b). Plasmid DNA that contained an insert of expected molecular size was isolated by the GenElute ${ }^{\mathrm{TM}}$ HP Plasmid Midiprep Kit (Sigma-Aldrich Chemie $\mathrm{GmbH}$ ), purified using the QIAquick Gel Extraction Kit (Qiagen) and automatically sequenced.

Total RNA isolation. Total RNA was isolated using TRIzol reagent (Invitrogen) according to the manufacturer's protocol. Cell homogenization was carried out on ice in a sterile glass homogenizer using $0.25-0.5 \mathrm{~mm}$ glass beads (Carl Roth $\mathrm{GmbH}$ and Co.). Any contaminating DNA was removed by treatment with RNase-free DNase I (Promega). RNA concentration was determined spectrophotometrically.

Southern blot hybridization. DNA was isolated, digested with restriction enzymes, electrophoresed (10 $\mu \mathrm{g}$ per lane) and blotted as described before (Subramanian et al., 1994). Hybridization was performed at $55^{\circ} \mathrm{C}$ with the cloned $R a b 7 a$ as the probe that was labeled with digoxygenin-11-dUTP (Roche) using Nick Translation System (Promega). Chemiluminescent detection was performed as described in (Wyroba et al., 1995).

Northern blot hybridization. Total RNA (20 $\mu \mathrm{g}$ ) of was electrophoresed on a formaldehyde/ $\%$ agarose gel and transferred to a positively charged nylon membrane (Boehringer Mannheim). Hybridization with digoxygenin-11-dUTP-labeled Paramecium $R a b 7 b$ cDNA as the probe was carried out at $50^{\circ} \mathrm{C}$ in Dig Easy Hyb (Roche) and blots were processed as in (Platek et al., 1999) except for maleate buffer (100 mM maleic acid, $150 \mathrm{mM} \mathrm{NaCl}$; pH 7.5) used in the blocking/washing procedures.

Computer analysis. Sequence searches were performed by the BLAST algorithm (Altschul et al., 1997) on NCBI databases. Multiple sequence alignment was carried out using the CLUSTAL W (1.82) program (Thompson et al., 1994).

\section{RESULTS AND DISCUSSION}

\section{Cloning of Paramecium Rab7 genes}

We identified two genes encoding Rab7 in Paramecium by PCR with primers designed from 
the amino-acid sequence of domains conserved in Rab7 of different species. Due to deviations from the universal genetic code in ciliates (Martindale, 1989) these primers were synthesized as degenerate oligonucleotides.

Different sets of primers generated PCR products of different lengths (not shown). Subcloning and sequencing of these products revealed that PCR products of $703 \mathrm{bp}$ and $706 \mathrm{bp}$ encoded Rab7a (Fig. 1, lane 1) and Rab7b (Fig. 1, lane 3), respectively. Subsequently, the sets of primers that enabled identification of these genes were used for RT-PCR and generated single products of about $600 \mathrm{bp}$ which upon subcloning and sequencing gave cDNA sequences encoding Rab7a (Fig. 1, lane 2) and Rab7b (Fig. 1, lane 4).

The Rab7a gene (accession number AY050242) of $703 \mathrm{bp}$ and Rab7b (accession number AY875981) of $707 \mathrm{bp}$ are $88.9 \%$ identical (including introns). These sequences show features typical for genes of ciliates: short introns, a high $\mathrm{A}+\mathrm{T}$ content and inframe universal stop codon (TAA and TAG) coding for glutamine (Martindale, 1989; Russell et al., 1994). Both genes have three introns of different length (28-32 bp) and sequence located at identical positions (Fig. 2). The cloned cDNAs for Rab7a and Rab7b (accession numbers AY744503, AY644723) are 618 nucleotides in length and $92.6 \%$ identical.

Paramecium Rab7a and Rab7b contain open reading frames encoding proteins of 206 amino acids. These deduced amino-acid sequences are 97.6\% identical. There are five amino acid exchanges (two

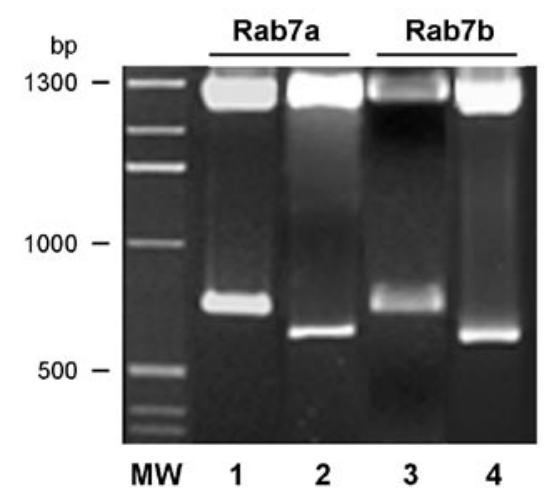

Figure 1. Agarose gel electrophoresis of isolated plasmids containing $R a b 7$ inserts.

Following subcloning into pGEM-T vector of PCR/RT-PCR products obtained with $R a b 7$-specific primers, the plasmids were isolated from positive colonies and digested with EcoRI. The presence of inserts of correct sizes was detected. Lanes 1 and 3 show inserts of predicted molecular size of about $700 \mathrm{bp}$ originated from PCR products which upon sequencing resulted in the cloning of Rab7a (lane 1) and $R a b 7 b$ (lane 3). Lanes 2 and 4 show inserts of about $620 \mathrm{bp}$ originated from RT-PCR products which upon sequencing resulted in cloning of cDNA for Rab7a (lane 2) and Rab7b (lane 4). The molecular mass standard (MW) is indicated on the left. of which are conserved) over the full length of the two polypeptides (Fig. 2).

The predicted protein sequences of Rab7a and Rab7b contain all the characteristic and highly conserved domains essential for Rab function: the effector (YRATVGADF) and nucleotide binding domains by phosphate (GDSGVGKT, WDTAGQ) and guanine (NKLD, SAK) as well as the prenylation motif $(-C C)$ at the C-terminus (Fig. 2). This posttranslational modification is present in all Rab proteins and is essential for membrane binding (Bruckert et al., 2000).

These are the first genes encoding Rab GTPases to be identified in Paramecium. Only short gene fragments homologous to Rab1, Rab2 and Rab5 were previously amplified by others (Fraga \& Hinrichsen, 1994), whereas we cloned the effector and nucleotide binding domain of Rab1 and Rab11 (accession numbers AY228708 and AY228707, respectively). In the ongoing project of Paramecium Genome Sequencing (Sperling et al., 2002) of another strain - P. tetraurelia d4-2 (http://www.genoscope.cns.fr) - some sequences exhibiting homology to Rab7 genes cloned by us may be found.

Many Rab GTPases seem to be products of gene duplication (Stenmark \& Olkkonen, 2001). However, up to now, Rab7 isoforms have been identified only in human and plants. Rab7b - a new human isoform of Rab7 GTPase recently just reported - was shown to be involved in monocytic differentiation of acute promyelocytic leukemia cells (Yang et al., 2004). Two flowering plants Nicotiana tabacum and Lotus japonicum express more than one isoform of Rab7 (four and three, respectively) (Haizel et al., 1995; Borg et al., 1997). Recent gene duplication has previously been reported in Paramecium: two isoforms of proton-translocating pyrophosphatase that display 94\% homology (Perez-Castineira et al., 2002) were identified. We described two genes encoding dynamin - another protein essential in the endocytic processes (Wiejak et al., 2004b).

\section{Southern blot analysis}

Southern blot analysis of Paramecium DNA digested with EcoRI, XbaI, EcoRV, BglII, HindIII and PstI using the cloned Rab7a as the probe was performed (Fig. 3). The hybridization pattern revealed an excessive number of hybridizing DNA fragments (Fig. 3) in comparison to the number of restriction sites in this gene (Table 1). Although there are no restriction sites for EcoRI and XbaI in Rab7a, two bands were observed in each case. Only one restriction site was mapped for BglII and EcoRV in Rab7a gene, but three DNA hybridizing species were detected. Finally, there are two restriction sites for HindIII and PstI each, whereas five and four DNA fragments, respectively, were observed. 


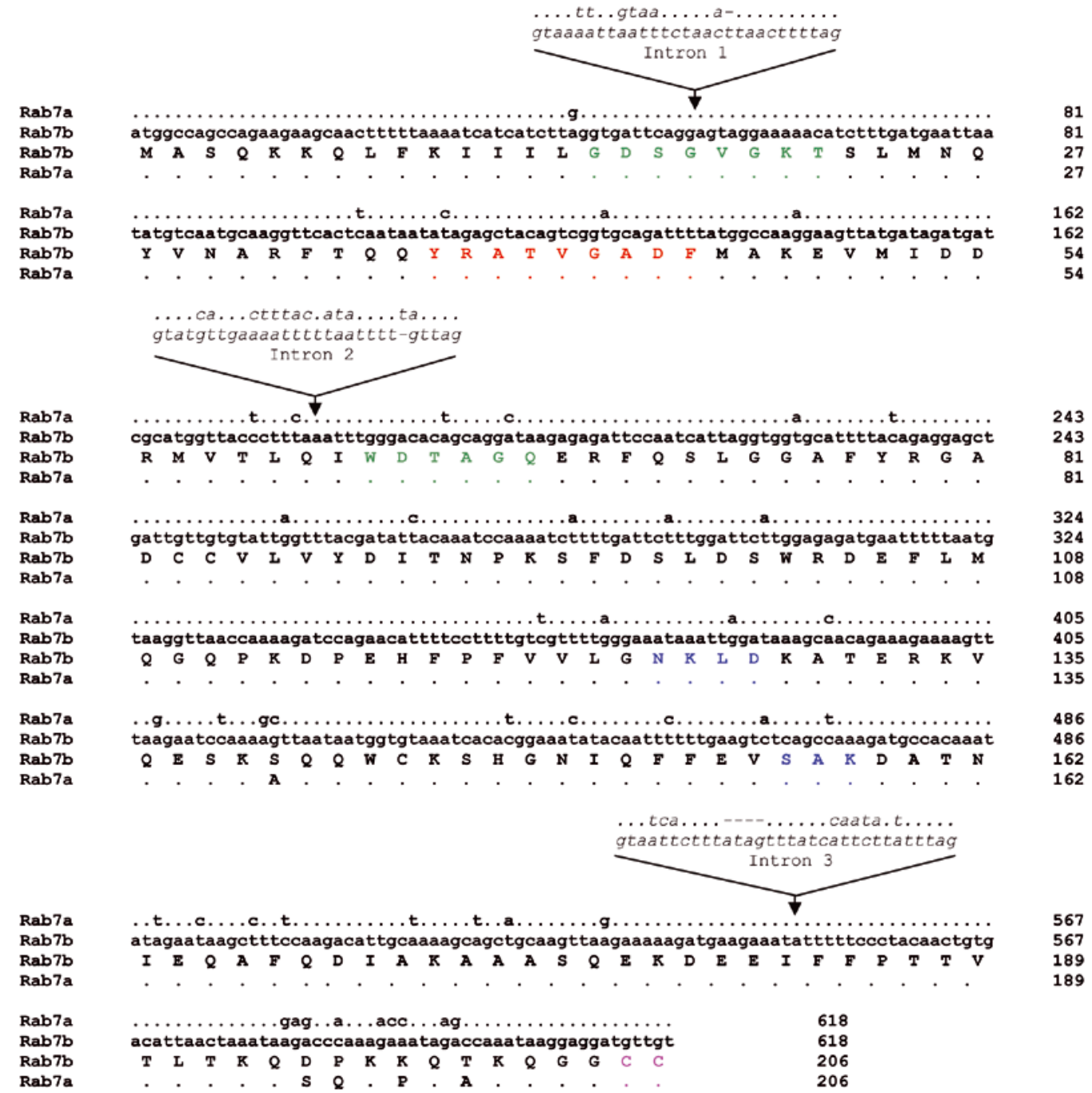

Figure 2. Nucleotide and deduced amino-acid sequences of Paramecium Rab7a and Rab7b.

The top two lines in each group show nucleotide sequences derived from cDNAs (accession numbers AY744503, AY644723) and the bottom two lines show the respective deduced amino-acid sequences (single-letter code). Dots indicate identical nucleotides or amino acids. Positions of three introns (italics) deriving from the genomic sequences (accession numbers AY050242, AY875981) are indicated by arrows: the top line in Rab7a gene and the bottom in Rab7b gene. Evolutionarily conserved domains are shown: effector domain (red), guanine base- (blue) and phosphate-binding motifs (green) and cysteine motif (pink).

However, the Rab7b gene contains only one restriction site for HindIII (Table 1). Thus, a comparison of the number of the hybridizing DNA fragments with the number of restriction sites for six different restriction enzymes in both cloned Rab7 genes confirms that two genes encoding this protein exist in Paramecium genome.

\section{Analysis of Rab7 expression and multiple sequence alignment}

Expression of Paramecium Rab7 genes was assessed by RT-PCR - as described above (Fig. 2) and by Northern blotting.

Northern blot analysis of total RNA extracted from Paramecium cells probed with the Rab7b cDNA revealed the presence of two transcripts of about 1.8 and $2.2 \mathrm{~kb}$ (Fig. 4) that most probably corresponded to the two Rab7 isoforms since the cloned cDNAs for Rab7a and Rab7b were 92.6\% identical (Fig. 2). Two messenger RNAs for Rab7 were previously found in human, mouse and rat (Vitelli et al., 1996).

Multiple alignment based on NCBI GenBank data indicates that the Paramecium Rab7a and Rab7b exhibit $62.3-63.3 \%$ identity to human, rat and mouse counterparts, $61.2-61.7 \%$ to Rab7 from Dictyostelium discoideum, 64.4-64.6\% to Trypanosoma cruzi Rab7 and 60.1-60.2\% to that from Leishmania major (Fig. 5). Paramecium Rab7 isoforms display $48.1-52.4 \%$ identity to Ypt7 of Saccharomyces cerevisiae, the yeast homologue of Rab7 involved in vacuolar transport (Wichmann et al., 1992). In the GenBank there is a sequence of a Rab7 gene of another ciliate Tetrahymena thermophila, but there is no data about its expression and func- 


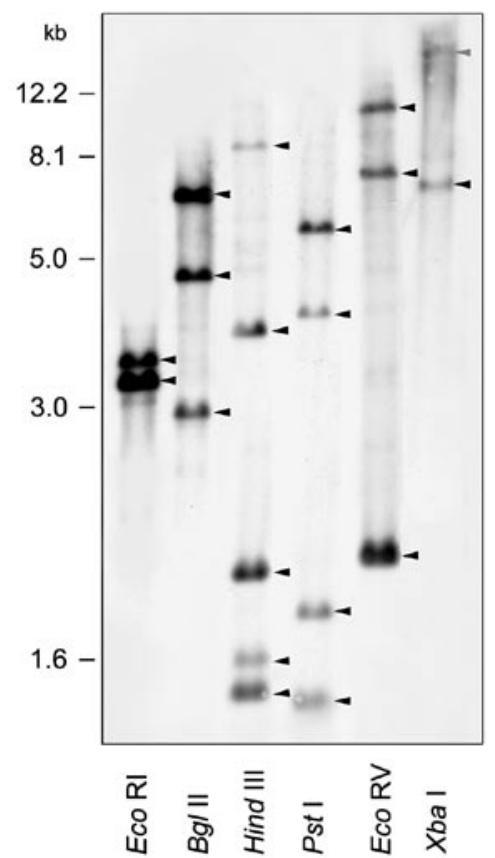

Figure 3. Southern hybridization analysis of Paramecium DNA restriction digests with Rab7-specific probe.

Paramecium DNA at $10 \mu \mathrm{g}$ per lane was digested with EcoRI, XbaI, EcoRV, BglII, HindIII and PstI, respectively, run in $0.8 \%$ agarose gel, transferred onto nylon filters and hybridized with the cloned Paramecium Rab7a gene as the probe labeled with digoxygenin-11-dUTP.

tion in this cell. The deduced amino-acid sequence displays $71.8 \%$ identity to Paramecium Rab7.

The prenylation motif $(-\mathrm{CC})$ present in Paramecium Rab7 isoforms is the same as in D. discoideum, whereas other protozoa, T. thermophila and Entamoeba histolytica (Welter et al., 2002), as well as yeast and mammals have a CXC motif (Pereira-Leal \& Seabra, 2001). Isoforms of Rab7 (EhRab7) have recently been identified in E. histolytica, some of them with atypical C-terminus and no cysteine (Saito-Nakano et al., 2005).

The overall predicted protein sequences of both Paramecium Rab7 isoforms are more similar to the mammalian counterparts than to Rab7 deriving from some parasitic protozoa. A survey of NCBI GenBank data revealed that two Rab7 sequences

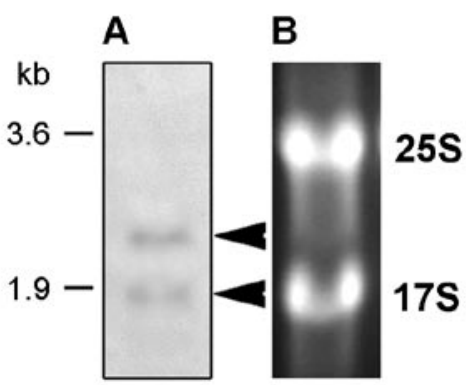

Figure 4. Northern blot analysis of Paramecium Rab7 mRNA.

A. Total RNA $(20 \mu \mathrm{g})$ was electrophoresed in a denaturing $1 \%$ agarose gel and transferred to a nylon membrane. Hybridization was carried out with digoxygenin-labeled Paramecium Rab7b cDNA as the probe. Two identified transcripts are indicated by arrows. B. Migration of ribosomal RNAs (25S and 17S) visualized by ethidium bromide staining performed prior to blotting and hybridization shown in A.

from the Kinetoplastida T. cruzi and L. major contain an insertion of 20 residues starting at position 147 that precedes the G4 domain (Denny et al., 2002). Such an insertion is not present either in Paramecium or in evolutionary younger $D$. discoideum and mammalian Rab7 proteins (Fig. 5). Interestingly, this region of the gene is close to the hot spot for mutations in human Rab7 at Asp161/Thr and Val162/Met causing ulcero-mutilating neuropathy of CharcotMarie-Tooth type 2B (Verhoven et al., 2003; Houlden et al., 2004). There is also a short deletion in a region preceding the G3 motif in Kinetoplastida Rab7 (Fig. 5) which is not present in Rab7 of Paramecium and those of higher eukaryotes (Denny et al., 2002). This region may contribute to different location/function of Rab7 proteins (Dunn et al., 1993). In fact, Araripe and coworkers (2004) localized Rab7 in T. cruzi at the Golgi apparatus using a specific antipeptide antibody.

Two conserved motifs characteristic for Rab GTPases, RabF and RabSF (Pereira-Leal \& Seabra, 2001), may be found in Paramecium Rab7 proteins (Fig. 5). Effectors and regulators of Rab proteins bind both to the RabF motifs in the switch I and II

Table 1. Comparison of the number of restriction sites in Paramecium Rab7 genes with the number of hybridizing DNA fragments in Southern blot analysis shown in Fig. 3, performed with cloned Rab7a gene as the probe.

\begin{tabular}{|c|c|c|c|c|c|c|c|}
\hline \multicolumn{2}{|c|}{ Restriction enzymes } & EcoRI & $B g l \mathrm{III}$ & HindIII & Pst I & EcoRV & $X b a \mathrm{I}$ \\
\hline \multirow{3}{*}{ 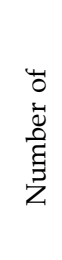 } & $\begin{array}{l}\text { restriction } \\
\text { sites in } R a b 7 a\end{array}$ & - & 1 & 2 & 2 & 1 & - \\
\hline & $\begin{array}{l}\text { restriction } \\
\text { sites in } R a b 7 b\end{array}$ & - & - & 1 & - & - & - \\
\hline & $\begin{array}{l}\text { hybridizing } \\
\text { DNA fragments }\end{array}$ & 2 & 3 & 5 & 4 & 3 & 2 \\
\hline
\end{tabular}




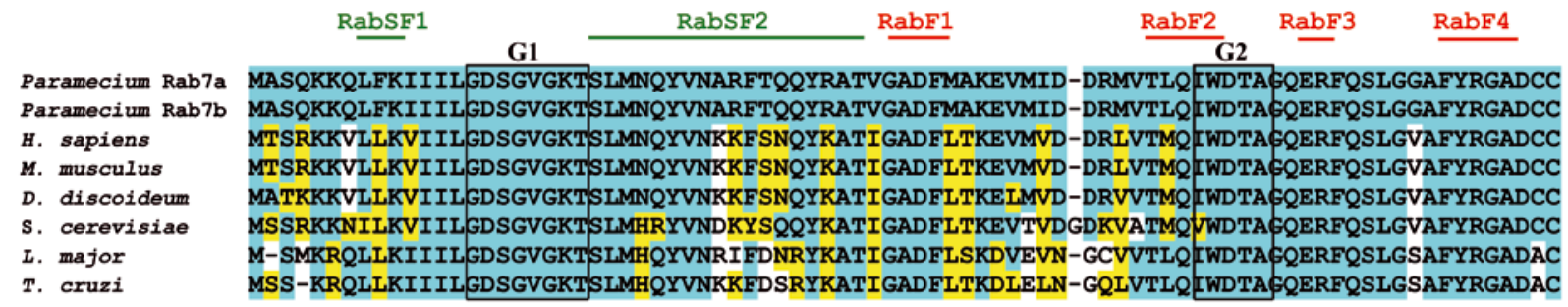

\begin{tabular}{|c|c|c|}
\hline & RabSF3 & \\
\hline & & ดั - \\
\hline Iramecium Rab7a & VLVYDITNPKSFDSLDSWRDEFLMQGQPKDPEHFPFVVL & KIDKAT-E-RKV-QESKAQQWCKSHG--------- \\
\hline aramecium Rab7b & VLVYDITNPKSFDSLDSWRDEFLMQGQPKDPEHFPFVVI & GNKLDKAT-E-RKV-QESKSQQWCKSHG----------------- \\
\hline H. sapiens & VLVFDVTAPNTFKTLDSWRDEFLIQASPRDPENFPFVVL & GNKIDLE--N-RQV-ATKRAQAWCYSKN- - \\
\hline M. musculus & VLVFDVTAPNTFKTLDSWRDEFLIQASPRDPENFPFVVI & GNKIDLE--N-RQV-ATKRAQAWCYRKN- - \\
\hline D. discoideum & VLCYDVNVAKTFENLDSWRDEFLIQAGPRDPDNFPFVVL & 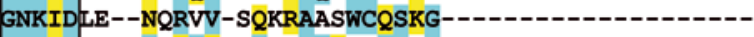 \\
\hline S. cerevisiae & VLVYDVTNASSFENIKSWRDEFLVHANVNSPETFPFVII & GNKIDAE--ESKKIVSEKSAQELAKSLG------------------- \\
\hline L. major & ILVFDVTQQESFAHVGSWLEEFSIQAGRRDS-----VLV & GNKTDLE--DRRQV-ASKTVQAWCAKQNAEAANAINGACAGAGDSAAP \\
\hline . cruzi & ILVFDVTQQESFSHISSWLEEFNIQAGKRDS-----VLI & GNKTDLA--DRRQV-ASKTAQAWCAAQSGEAAAASGGSSITASGSGGC \\
\hline
\end{tabular}

Paramecium Rab7a Paramecium Rab7b

H. sapiens

M. musculus

D. discoideum

S. cerevisiae

L. major

T. cruzi

G4

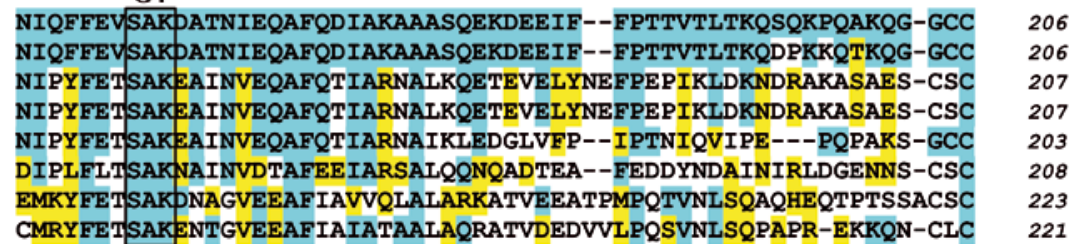

Figure 5. Multiple alignment of the deduced amino-acid sequences of Paramecium Rab7a (accession number AAL08054) and Rab7b (accession number AAW68046) with Rab7 proteins from different species using CLUSTAL W (1.82) program.

Homo sapiens (NP_004628), Mus musculus (NP_033031), Dictyostelium discoideum (AAA80152), Saccharomyces cerevisiae (P32939), Leishmania major (CAB75350) and Trypanosoma cruzi (AAD32707). Amino acids are shown in single-letter code. Identical residues are marked blue and similar ones - yellow. Four GTP binding sites (G1-G4) are boxed. Five Rab-specific motifs (RabF) and three Rab subfamily regions (RabSF) are indicated.

regions, to discriminate between active and inactive conformations, and to RabSF regions for specificity (Pereira-Leal \& Seabra, 2001; Stenmark \& Olkkonen, 2001).

Previously, when we cloned the effector domain of the first gene encoding Paramecium Rab7 (which later we defined as Rab7a), an antibody against human Rab7 was used for localization studies that revealed labeling of the phagosomal membrane in Paramecium (Surmacz et al., 2003) and Rab7 colocalization with its effector protein, RILP (Rab-interacting lysosomal protein)*.

RILP induces recruitment of the dynein-dynactin motor to late endosomes/lysosomes and enables the movement of these organelles along microtubules (Jordens et al., 2001). Thus, our result is consistent with the concept of Rab7 participation in the transport of internalized compounds from the early to the late endocytic/lysosomal compartment as observed in mammalian cells (Pfeffer \& Aivazian,
2004). Now, when two genes encoding Rab7 in Paramecium have been identified, elucidation of the exact biological role of both isoforms will require an extensive proteomic analysis, bearing in mind that there are only five amino acid exchanges over the full length of the two polypeptides. It is worth noticing that four of those substitutions are located in the Cterminal hypervariable region that mainly specifies the location/function of Rab7 proteins (Chavrier et al., 1991; Bruckert et al., 2000; Moyer \& Balch, 2001).

\section{Acknowledgements}

This research was supported by the statutory funds to the Nencki Institute of Experimental Biology.

\section{REFERENCES}

Altschul SF, Madden TL, Schaffer AA, Zhang J, Zhang Z, Miller W, Lipman DJ (1997) Gapped BLAST and PSI-

*These results were presented at the FEBS Meeting 2005 in Budapest, Hungary, and published in: Surmacz L, Wiejak J, Wyroba E (2005) Two genes encoding Rab7 protein exist in unicellular eukaryote Paramecium. FEBS J 272: 330. 
BLAST: a new generation of protein database search programs. Nucleic Acids Res 25: 3389-3402.

Araripe JR, Cunha e Silva NL, Leal ST, de Souza W, Rondinelli E (2004) Trypanosoma cruzi: TcRAB7 protein is localised at the Golgi apparatus in epimastigotes. Biochem Biophys Res Commun 321: 397-402.

Borg S, Brandstrup B, Jensen TJ, Poulsen C (1997) Identification of new protein species among 33 different small GTP-binding proteins encoded by cDNAs from Lotus japonicus, and expression of corresponding mRNAs in developing root nodules. Plant J 11: 237-250.

Bruckert F, Laurent O, Satre M (2000) Rab7, a multifaceted GTP-binding protein regulating access to degradative compartments in eukaryotic cells. Protoplasma 210: 108-116.

Chavrier P, Gorvel JP, Stelzer E, Simons K, Gruenberg J, Zerial M (1991) Hypervariable C-terminal domain of rab proteins acts as a targeting signal. Nature 353: 769-772.

Creutz CE, Tomsig JL, Snyder SL, Gautier MC, Skouri F, Beisson J, Cohen J (1998) The copines, a novel class of C2 domain-containing, calcium-dependent, phospholipid-binding proteins conserved from Paramecium to humans. J Biol Chem 273: 1393-1402.

Croizet-Berger K, Daumerie C, Couvreur M, Courtoy PJ, van den Hove MF (2002) The endocytic catalysts, Rab5a and Rab7, are tandem regulators of thyroid hormone production. Proc Natl Acad Sci USA 99: 8277-8282.

Denny PW, Lewis S, Tempero JE, Goulding D, Ivens AC, Field MC, Smith DF (2002) Leishmania RAB7: characterisation of terminal endocytic stages in an intracellular parasite. Mol Biochem Parasitol 123: 105-113.

Desjardins M, Huber LA, Parton RG, Griffiths G (1994) Biogenesis of phagolysosomes proceeds through a sequential series of interactions with the endocytic apparatus. J Cell Biol 124: 677-688.

Dunn B, Stearns T, Botstein D (1993) Specificity domains distinguish the Ras-related GTPases Ypt1 and Sec4. Nature 362: 563-565.

Feng Y, Press B, Wandinger-Ness A (1995) Rab7: an important regulator of late endocytic membrane traffic. $J$ Cell Biol 131: 1435-1452.

Fraga D, Hinrichsen RD (1994) The identification of a complex family of low-molecular-weight GTP-binding protein homologues from Paramecium tetraurelia by PCR cloning. Gene 147: 145-148.

Haizel T, Merkle T, Turckand F, Nagy F (1995) Characterization of membrane-bound small GTP-binding proteins from Nicotiana tabacum. Plant Physiol 108: 59-67.

Houlden H, King RH, Muddle JR, Warner TT, Reilly MM, Orrell RW, Ginsberg L (2004) A novel RAB7 mutation associated with ulcero-mutilating neuropathy. Ann Neurol 56: 586-590.

Jordens I, Fernandez-Borja M, Marsman M, Dusseljee S, Janssen L, Calafat J, Janssen H, Wubbolts R, Neefjes J (2001) The Rab7 effector protein RILP controls lysosomal transport by inducing the recruitment of dyneindynactin motors. Curr Biol 11: 1680-1685.

Kissmehl R, Froissard M, Plattner H, Momayezi M, Cohen J (2002) NSF regulates membrane traffic along multiple pathways in Paramecium. J Cell Sci 115: 3935-3946.

Luporini P, Vallesi A, Miceli C, Bradshaw RA (1994) Ciliate pheromones as early growth factors and cytokines. Ann N Y Acad Sci 712: 195-205.

Martindale DW (1989) Codon usage in Tetrahymena and other ciliates. J Protozool 36: 29-34.

Meresse S, Steele-Mortimer O, Finlay BB, Gorvel JP (1999) The rab7 GTPase controls the maturation of Salmo- nella typhimurium-containing vacuoles in HeLa cells. EMBO J 18: 4394-4403.

Moyer BD, Balch WE (2001) Structural basis for Rab function: an overview. Methods Enzymol 329: 3-6.

Pereira-Leal JB, Seabra MC (2001) Evolution of the Rab family of small GTP-binding proteins. J Mol Biol 313: 889-901.

Perez-Castineira JR, Alvar J, Ruiz-Perez LM, Serrano A (2002) Evidence for a wide occurrence of proton-translocating pyrophosphatase genes in parasitic and freeliving protozoa. Biochem Biophys Res Commun 294: 567573.

Pfeffer S, Aivazian D (2004) Targeting Rab GTPases to distinct membrane compartments. Nat Rev Mol Cell Biol 5: 886-896.

Platek A, Wiejak J, Wyroba E (1999) RT-PCR and Northern blot analysis in search for a putative Paramecium betaadrenergic receptor. Acta Biochim Polon 46: 813-821.

Rak A, Pylypenko O, Niculae A, Pyatkov K, Goody RS, Alexandrov K (2004) Structure of the Rab7:REP-1 complex: insights into the mechanism of Rab prenylation and choroideremia disease. Cell 117: 749-760.

Rupper A, Grove B, Cardelli J (2001) Rab7 regulates phagosome maturation in Dictyostelium. J Cell Sci 114: 2449-2460.

Russell CB, Fraga D, Hinrichsen RD (1994) Extremely short 20-33 nucleotide introns are the standard length in Paramecium tetraurelia. Nucleic Acids Res 22: 1221-1225.

Saito-Nakano Y, Lotus BJ, Hall N, Nozaki T (2005) The diversity of Rab GTPases in Entamoeba histolytica. Exp Parasitol 110: 244-252.

Saraste J, Lahtinen U, Goud B (1995) Localization of the small GTP-binding protein rab1p to early compartments of the secretory pathway. J Cell Sci 108: 15411552.

Seabra MC, Wasmeier C (2004) Controlling the location and activation of Rab GTPases. Curr Opin Cell Biol 16: 451-457.

Sieczkarski SB, Whittaker GR (2003) Differential requirements of Rab5 and Rab7 for endocytosis of influenza and other enveloped viruses. Traffic 4: 333-343.

Sogin ML, Elwood HJ (1986) Primary structure of the Paramecium tetraurelia small-subunit rRNA coding region: phylogenetic relationships within the Ciliophora. J Mol Evol 23: 53-60.

Somsel Rodman J, Wandinger-Ness A (2000) Rab GTPases coordinate endocytosis. J Cell Sci 113: 183-192.

Sperling L, Dessen P, Zagulski M, Pearlman RE, Migdalski A, Gromadka R, Froissard M, Keller AM, Cohen J (2002) Random sequencing of Paramecium somatic DNA. Eukaryot Cell 1: 341-352.

Stenmark H, Olkkonen VM (2001) The Rab GTPase family. Genome Biol 2: 3007.1-3007.7.

Subramanian SV, Wyroba E, Andersen AP, Satir BH (1994) Cloning and sequencing of parafusin, a calcium-dependent exocytosis-related phosphoglycoprotein. Proc Natl Acad Sci USA 91: 9832-9836.

Surmacz L, Wiejak J, Wyroba E (2003) Evolutionary conservancy of the endocytic and trafficking machinery in the unicellular eukaryote Paramecium. Biol Cell 95: 69-74.

Thompson JD, Higgins DG, Gibson TJ (1994) CLUSTAL $\mathrm{W}$ : improving the sensitivity of progressive multiple sequence alignment through sequence weighting, position-specific gap penalties and weight matrix choice. Nucleic Acids Res 22: 4673-4680.

Van der Sluijs P, Gerez L (1999) Rab GTPases as regulators of transport through endosomes. Protoplasma 210: 1-10. 
Vitelli R, Chiariello M, Lattero D, Bruni CB, Bucci C (1996) Molecular cloning and expression analysis of the human Rab7 GTP-ase complementary deoxyribonucleic acid. Biochem Biophys Res Commun 229: 887-890.

Verhoeven K, De Jonghe P, Coen K, Verpoorten N, AuerGrumbach M, Kwon JM, FitzPatrick D, Schmedding E, De Vriendt E, Jacobs A, Van Gerwen V, Wagner K, Hartung HP, Timmerman V (2003) Mutations in the small GTP-ase late endosomal protein RAB7 cause Charcot-Marie-Tooth type 2B neuropathy. Am J Hum Genet 72: 722-727.

Welter BH, Laughlin RC, Temesvari LA (2002) Characterization of a Rab7-like GTPase, EhRab7: a marker for the early stages of endocytosis in Entamoeba histolytica. Mol Biochem Parasitol 121: 254-264.

Wichmann H, Hengst L, Gallwitz D (1992) Endocytosis in yeast: evidence for the involvement of a small GTPbinding protein (Ypt7p). Cell 71: 1131-1142.

Wiejak J, Surmacz L, Wyroba E (2004a) Dynamin-association with agonist-mediated sequestration of beta-ad- renergic receptor in single-cell eukaryote Paramecium. J Exp Biol 207: 1625-1632.

Wiejak J, Surmacz L, Wyroba E (2004b) Dynamin- and clathrin-dependent endocytic pathway in unicellular eukaryote Paramecium. Biochem Cell Biol 82: 547-558.

Wyroba E (1987) Stimulation of Paramecium phagocytosis by phorbol ester and forskolin. Cell Biol Int Rep 11: 657-664.

Wyroba E, Widding Hoyer A, Storgaard PS, Satir BH (1995) Mammalian homologue of the calcium-sensitive phosphoglycoprotein, parafusin. Eur J Cell Biol 68: 419-426.

Yang M, Chen T, Han C, Li N, Wan T, Cao X (2004) Rab7b, a novel lysosome-associated small GTPase, is involved in monocytic differentiation of human acute promyelocytic leukemia cells. Biochem Biophys Res Commun 318: 792-799. 